\title{
Assessment of Design and Retrofitting Solutions on the Progressive Collapse of Hongqi Bridge
}

\author{
Amir Seyed Khoei $\mathbb{D}^{1},{ }^{1}$ Reza Akbari, ${ }^{2}$ Shahrokh Maalek, ${ }^{3,4}$ and Alireza Gharighoran ${ }^{5}$ \\ ${ }^{1}$ Department of Civil Engineering, Isfahan (Khorasgan) Branch, Islamic Azad University, Isfahan, Iran \\ ${ }^{2}$ Road Maintenance and Transportation Organization (RMTO), Tehran, Iran \\ ${ }^{3}$ Iranian Bridge Engineering Association, Tehran, Iran \\ ${ }^{4}$ School of Civil Engineering, University of Tehran, Tehran, Iran \\ ${ }^{5}$ Department of Railway Engineering, Faculty of Transportation, University of Isfahan, Isfahan, Iran
}

Correspondence should be addressed to Amir Seyed Khoei; amir.khoei@gmail.com

Received 28 August 2019; Accepted 17 June 2020; Published 15 September 2020

Academic Editor: Mario Terzo

Copyright (c) 2020 Amir Seyed Khoei et al. This is an open access article distributed under the Creative Commons Attribution License, which permits unrestricted use, distribution, and reproduction in any medium, provided the original work is properly cited.

In 2009, the Hongqi Bridge, a multispan reinforced concrete bridge located in Zhuzhou, Hunan Province, China, collapsed progressively in the form of domino, due to extreme effect of deck to pier, during demolition process of the bridge. In this study, progressive collapse of Hongqi Bridge was investigated using nonlinear dynamic analysis in the Applied Element Method, which has been proven as one of the best methods that can follow the collapse behavior of structures. Good agreements were obtained between numerical results and field observations as well as previously reported results. After verifying the bridge collapse procedure, the effects of different alternatives for superstructure and substructure systems on the progressive collapse procedure were investigated. In addition, application of restrainers at the connection of deck to abutment was studied as an effective solution in order to prevent collapse propagation and to minimize associated damages. The results of the study showed that all chosen methods and factors could be helpful and effective in the procedure of collapse propagation for this kind of bridge.

\section{Introduction}

Progressive collapse (PC) is defined as an extension of a local failure in a structure from one element to another, finally resulting in the collapse of the whole or a large part of the structure [1]. Starossek classified PC mechanisms into six types including pancake type, domino type, zipper type, section type, instability type, and mixed type. In the dominotype progressive collapse, a substantial amount of potential energy is transformed into kinetic energy during the fall or overturning of elements and is subsequently reintroduced in the structure. In this type of collapse, principal forces of failing elements are orthogonal to the direction of failure propagation [2]. The collapse of Hongqi Bridge is categorized as a domino type of collapse.

After the collapse of the World Trade Center, located in New York City, USA, in 2001, several numerical PC analyses were carried out, which are limited to framed structures [3-6]. However, there are limited studies on PC of bridge structures. As one of the well-known bridge collapses, one may refer to the wind-induced collapse of the Tacoma Narrows Bridge in 1940. In this event, bridge hangers were failed and subsequent failure of stiffening plates of longitudinal beams was determined as the main reason for the bridge collapse [7]. The Silver Bridge, an eyebar-chain suspension bridge in Ohio, USA, collapsed without any alarm after 40 years of service in December 1967 because of the failure of an eyebar in a joint of the north eyebar suspension chain [7]. The Viadotto Cannavino Bridge, a four-span continuous girder bridge in Italy, collapsed progressively in 1972 during construction, after the failure of the bridge deck molds in some regions [8]. The Haengju Bridge, a continuous prestressed bridge in Seoul, South Korea, collapsed in 1992 when it was under construction. High stress level of the deck tendons was distinguished as the main cause 
of the bridge collapse [8]. The I-35 Mississippi River Bridge, a truss bridge with metal deck in Minneapolis, USA, collapsed progressively in 2007, due to the failure of a joint plate and a diagonal member [9]. The Xiayu Bridge, a 5-span prestressed bridge, damaged during the Wenchuan earthquake in China and 3 spans of the bridge collapsed progressively [10].

To obtain a reliable model of collapse incident of a structure, nonlinear dynamic analysis of a detailed model of the structure is required, which usually makes the solution of the problem time-consuming and difficult. Various methods of analysis are usually used such as Finite Element Method (FEM). Another newly expanded method is the Applied Element Method (AEM) considering element-by-element discretization during analysis and makes PC analysis more efficient. This method was firstly used by Lau and Wibowo as an appropriate technique for PC analysis of reinforced concrete bridges (2010). Ibarhim et al. conducted a PC analysis of posttensioned bridges with voided slab type of deck under blast loading using the AEM. This bridge type is more frequent in comparison with other types of bridges in the United States. Some parameters including different charge weight and position of explosive charge have been investigated and led to valuable results [11]. Lu and Zhang conducted PC analysis on the pile foundation of a bridge due to ship collision. A ship clashed to the pier of the Jiujiang Bridge, a $675 \mathrm{~m}$ long bridge in China, and impacted pier together with the 2 adjacent piers were extremely damaged and $200 \mathrm{~m}$ of the bridge collapsed consequently [12]. Xu et al. simulated PC analysis of a multispan stone arch bridge. They simulated real collapse procedure and investigated important factors [13]. Salem and Helmy investigated the cause of I-35 bridge collapse using AEM and developed the bridge model by considering all structural details and loading condition at the time of the collapse. Finally, they found a good agreement between the cause and procedure of collapse and field investigations of the collapsed bridge [14]. Kiaming et al. analyzed PC of Hongqi Bridge, using the AEM. One of the bridge piers was unpredictably collapsed in 2009 due to improper selection of destruction method, and the next 8 spans of the bridge were collapsed subsequently [15]. In [16], Seyed Khoei, Akbari, and Maalek conducted a research on earthquake-induced dominotype progressive collapse in regular, semiregular, and irregular bridges using AEM method.

Regarding the importance and application of $\mathrm{PC}$ analysis for the assessment of the behavior of bridges against different loading conditions, in this study, domino-type progressive collapse of Hongqi Bridge was investigated by nonlinear dynamic analysis using AEM. The simulated collapse procedure of the bridge that occurred due to inaccurate mechanical demolition method was compared with the results of finite element simulation and field observations. Alternative practical solutions for designing and retrofitting of the bridge were applied to the verified bridge model, and the efficiency of each solution was assessed.

\section{A Short Review of the Applied Element Method}

The AEM is a method capable of simulating a structure through the continuum and discrete stages proposed by
Tagel-Din and Meguro [17]. Thus, it has been proven to be the best method that can follow collapse behavior of a structure under dynamic analysis through all stages of material behavior such as linear behavior, start and propagation of crack in tension-weak materials, yielding of reinforcement, separation of adjacent element, and collision (contact) of separated element with neighboring structures or ground [18]. As shown in Figure 1, in AEM, the structure is an assembly of elements connected to each other through adjacent surfaces using a pair of normal and shear springs distributed on each face of elements. Connector springs are responsible for the state of strains and quantity of stresses generated during analysis and yielding and failure criteria. The springs represent the behavior of assigned materials such as concrete, steel, or masonry materials.

In AEM, 3 translations and 3 rotations of degrees of freedom are considered for a single element calculated at the center of gravity of the element. Relative displacements and rotations between each of two adjacent elements cause stresses in springs, and element connectivity can be separated once average strain between two adjacent faces reaches a specified limit, and afterwards, separated elements are assumed as a rigid body during remnant of analysis. In a probable collision between these rigid bodies and the other structural elements or ground, a new set of springs called contact springs are generated and collision would follow impact rules. To model reinforcement bars, the element is represented by element springs and reinforcement springs. Reinforcement springs have the same material properties, exact location, and dimension of represented rebar. Normal spring direction is taken as the direction of the rebar perpendicular to element face direction.

Fully nonlinear path-dependent constitutive models are adopted in AEM as shown in Figure 2. As shown in Figure 2(a), an elastoplastic and fracture model is adopted for concrete in compression [19]. A linear stress-strain relationship is adopted for concrete in tension, before cracking of the concrete, and the stresses drop to zero after cracking. In the next loading step, then, residual stresses are redistributed by implementing a force with the same value but in the reverse direction. Stress-to-strain ratio is assumed linear for concrete in shear as long as the concrete is not cracked. After cracking, shear stresses drop down as shown in Figure 2(b). This drop level depends on aggregate interlock and friction of the crack surface.

As shown in Figure 2(c), the constitutive model introduced by Ristic et al. [20] is used for steel reinforcement bar in axial loading. In this model, the stress-to-strain ratio of reinforcement steel is not constant and depends on various factors such as amount of strain in spring, loading status (loading or unloading stage), and the Bauschinger effect showing the previous history of steel spring. Using this model, the effects of partial unloading and Bauschinger effect can easily be considered without any additional calculation in the analysis process. Shear stress-to-shear strain ratio is assumed elastic for reinforcement steel in shear. Steel reinforcement spring rupture in failure strain is defined for steel material. 


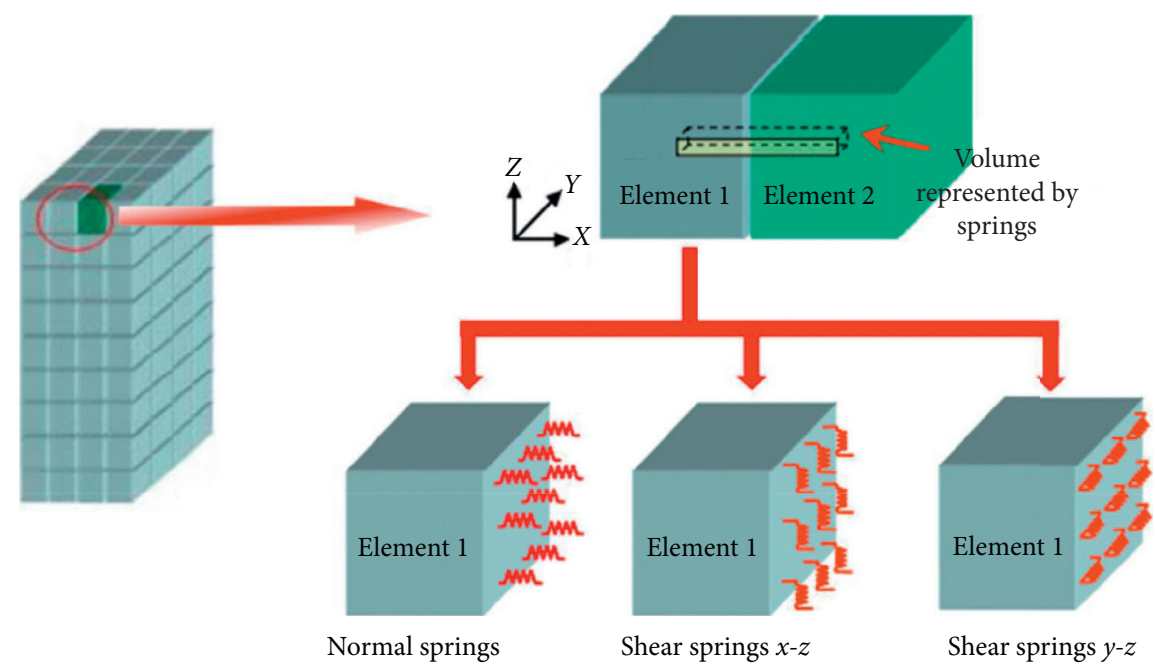

FIGURE 1: Element connections in AEM.

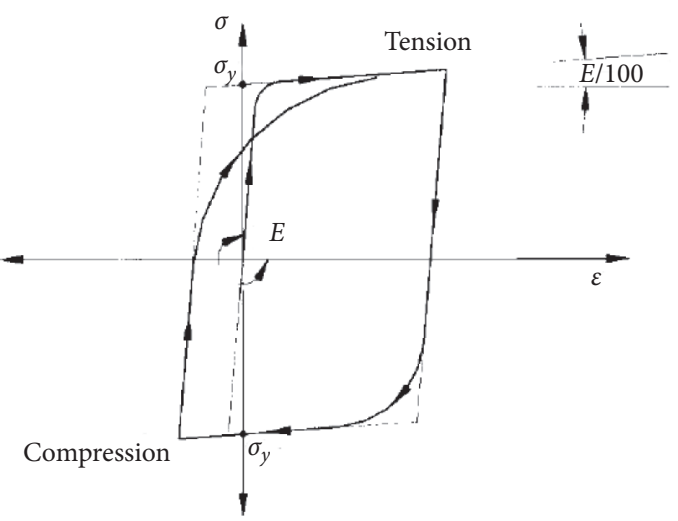

(a)

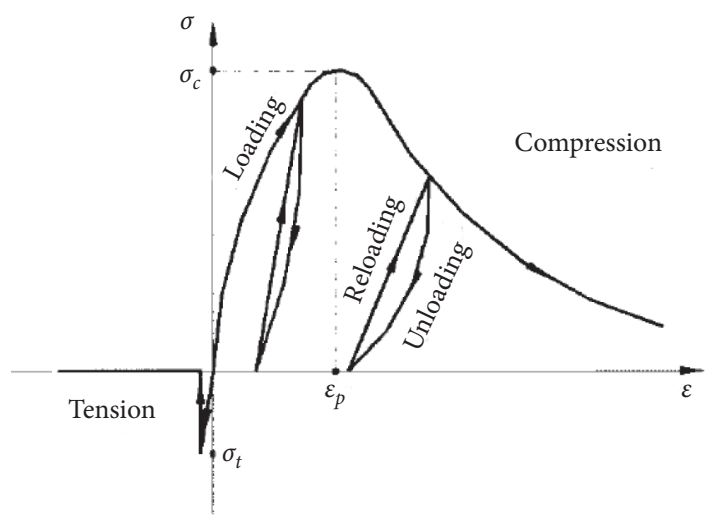

(b)

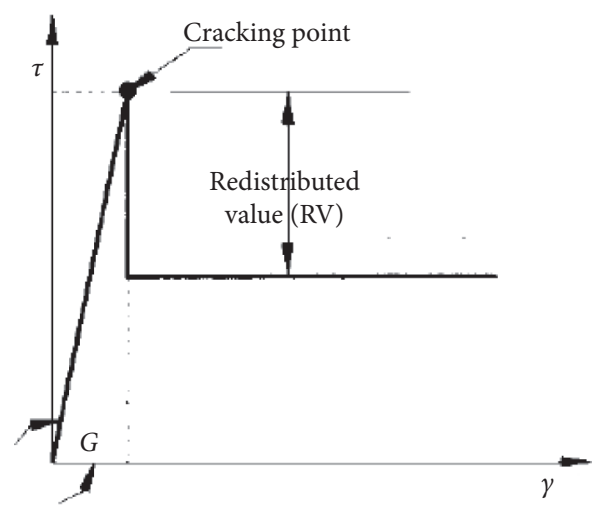

(c)

FiguRE 2: The constitutive models for (a) concrete under axial stress [19], (b) steel reinforcement bar under axial stress [20], and (c) concrete under shear stress.

\section{The Bridge under Study}

3.1. Bridge Specifications. In this study, the Hongqi Bridge, a multispan simply supported bridge in Zhuzhou city in Hunan Province, China, was selected to be investigated. It was a bridge with 122 spans and a total length of $2329 \mathrm{~m}$. Each span consisted of 16 hollow prestressed concrete slabs with a length and width of $0.85 \mathrm{~m}$ and $1 \mathrm{~m}$, respectively, formed a voided slab deck with a total width of $16.5 \mathrm{~m}$. The decks were supported on the piers through 7808 elastomeric bearings. The pier height from the pile cap was $7.875 \mathrm{~m}$ with a thickness of $0.8 \mathrm{~m}$. The geometrical properties of the piers and reinforcement detailing have been extracted from [15]. 
3.2. Bridge Demolition. In 2009, the government decided to demolish the Hongqi Bridge in a preorganized plan. They adopted two various ways for it; the first method was blasting demolishing and the second one was mechanically demolishing the bridge spans. Until pier \#100, the bridge was demolished through the first method, and for other spans, the second method was used. In the planned procedure for the mechanical method, the first phase was to eliminate the concrete between each of two hollow slabs; after that, the end of the first hollow slabs, at the location of $1.4 \mathrm{~m}$ from the left side of the slab, would be demolished by a hydraulic breaker which is in the adjacent span, as shown in Figure 3. The first separated hollow slab would fall on the ground. By the same pattern, the second hollow slab and other 14 slabs would be separated and fell down until the whole span demolished. Unfortunately in the implemented demolishing procedure, to accelerate the process, the last four hollow slabs, which are slabs $13,14,15$, and 16, were demolished simultaneously without removing the concrete between two adjacent slabs in one stage and other 12 slabs in the next stage.

This resulted in falling down the 12 slabs on the ground together. The left sides of the slabs felt down on the ground and the right sides collided with pier \#109.

A big impact force was applied to pier \#109 due to this collision. The impact force was extremely bigger than the designed shear capacity of the pier and resulted in the collapse of pier \#109. Consequently, the next span, between piers \#109 and \#108, lost its support and collided with pier \#108, which resulted in collapse of this pier. The other 7 spans collapsed with a similar pattern which resulted in domino-type progressive collapse. The collapse process stopped at pier \#101. This pier deformed, but did not collapse. All collapsed spans and piers had the same construction details, but it has not been exactly answered way the pier \# 101 did not collapse.

3.3. Material Properties. Characteristics of the materials used in this study were in accordance with the site under study. After the incident, an investigation team was organized to collect the samples from spans and piers. Collected samples were tested at the structural lab in Central South University in Changsha, China. According to laboratory analysis, the average compressive strength of concrete was considered as $64.1 \mathrm{MPa}$ and $38.7 \mathrm{MPa}$ for slabs and piers, respectively. Average yield strengths were equal to $347 \mathrm{MPa}$, $498 \mathrm{MPa}$, and $470 \mathrm{MPa}$ for $\varnothing 18, \varnothing 12$, and $\varnothing 10$ bars, respectively, and average ultimate strengths of $\varnothing 18, \varnothing 12$, and $\emptyset 10$ bars were equal to $526 \mathrm{MPa}, 571 \mathrm{MPa}$, and574 MPa, respectively, based on field observation [15].

3.4. Bridge Simulation. The AEM was used for simulation of the Hongqi Bridge, as shown in Figure 4. This method has been frequently used for such analysis with successful results. To minimize calculation costs, just 2 spans ( 3 piers) of the bridge were initially considered for verification analysis. Finer mesh resolution was used in the areas with higher stress concentration and probable impact or significant deformation location.
3.4.1. Validation Analysis. As shown in Figure 4, at $1.4 \mathrm{~m}$ from the left side of the first span, 1-12 hollow concrete slabs were demolished together in accordance with real practice. Then, the bridge model was analyzed dynamically in AEM and the results of different stages were extracted as clearly shown in Figure 5. After removing the abovementioned part, the left side of the span fell down on the ground and the right side affected with pier \#109. Due to this impacting, severe shear force was applied to the pier in the longitudinal direction of the bridge. Consequently, the pier damaged severely and collapsed. Falling down of adjacent span with the same pattern resulted in a huge impacting force on pier \#108 and the collapse propagated progressively in the longitudinal direction of the bridge.

After completion of the collapse procedure of the span, the height of the remained part of pier \#109 in AEM was compared with the results of the previously reported analysis in FEM as well as the field observations, as presented in Figure 6. As illustrated in Figure 6, the height of the remained part of the pier is in good agreement with the FEM results and field observations. Figure 7 shows the results of the comparison of maximum impacting force imposed to pier \#109 in AEM with FEM [15]. As depicted in Figure 7, impacting force obtained in this study, using AEM, is so close to the corresponding magnitude in the previously reported FEM analysis. As a result, it can be claimed that the model of Hongqi Bridge was verified correctly in AEM.

The differences between the results obtained from the AEM and FEM can be attributed to the fact that, in FEM analysis, to minimize calculation costs, if strain values in each element become more than 0.3 , thus that element would be removed from the analysis. Therefore, there was no interlayer friction between separated elements. However, in this study, by modeling the structure in AEM, the collapse process of the structure reliably continued and no elements were removed during the analysis. As a result, separated elements fell down and collided with the remainder structure as debris and the friction between fallen deck, pier \#109, and this debris caused the time of collision to be lengthy. Thus, the procedure of progressive collapse in FEM became faster than AEM, in which time of collision between fallen span and pier \#109 was equal to $1.24 \mathrm{~s}$, while it was equal to $1.33 \mathrm{~s}$ in FEM. In the process of analysis, it was observed that the time of collapse of pier \#109 was equal to $3.03 \mathrm{~s}$ in AEM, while it was equal to $2.00 \mathrm{~s}$ in FEM.

\section{Effects of Different Structural Systems on PC}

4.1. Effect of Type of Superstructure. Original deck of Hongqi Bridge was composed of 16 hollow concrete slabs, formed a voided slab deck. According to validation results, wrong administration of mechanical method of demolition for 12 hollow slabs of 2 spans resulted in a huge impacting force of $18 \mathrm{MN}$ and collapse of both spans. In this section, 4-span Hongqi Bridge with a complete 16-slab deck was modeled to study the progressive collapse procedure of multispan bridges. To investigate the effect of type of deck on PC procedure of the bridge, the concrete girder-slab and steel girder-slab decks were considered with respect to the design 


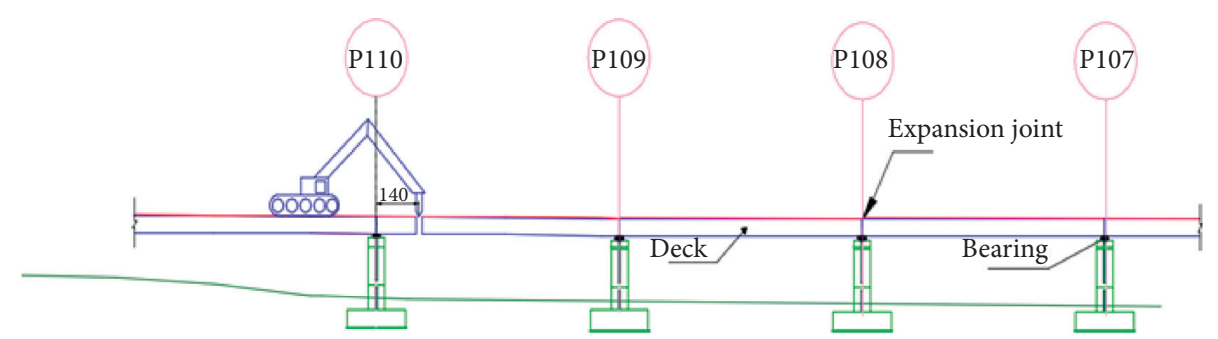

Figure 3: The mechanical demolishing plan of the span.

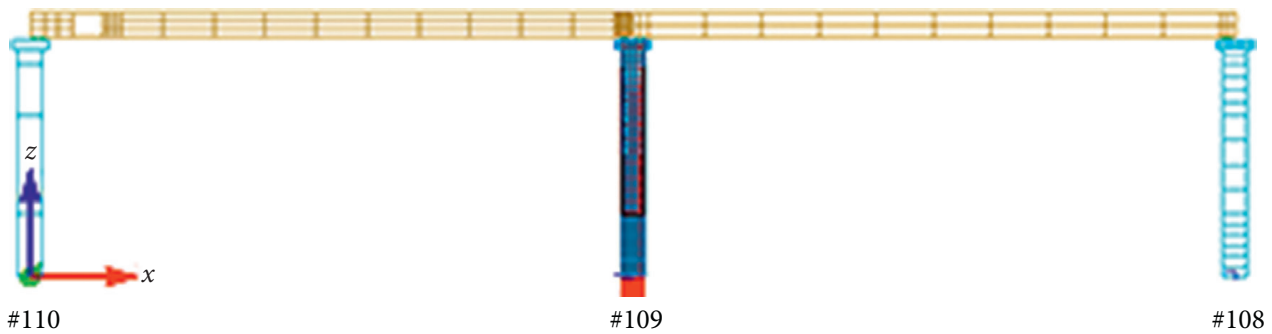

Figure 4: Mesh details of two spans of Hongqi Bridge in AEM.

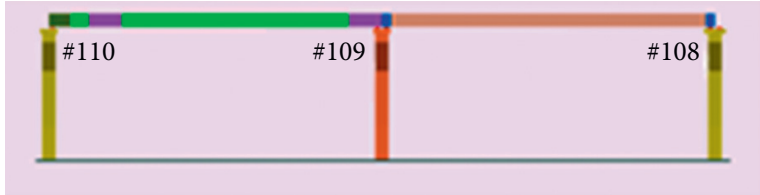

(a)

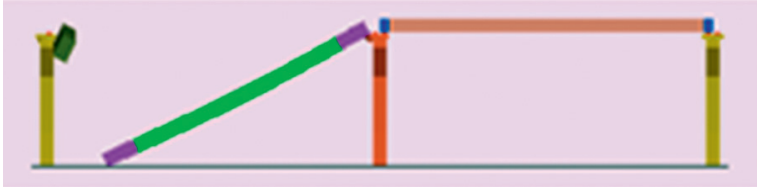

(c)

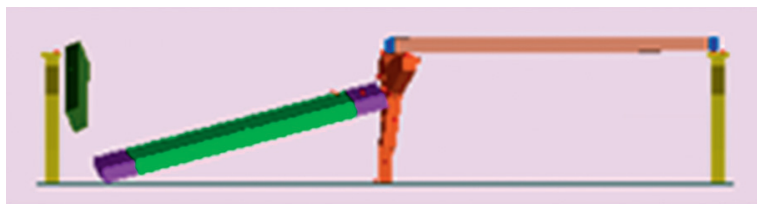

(e)

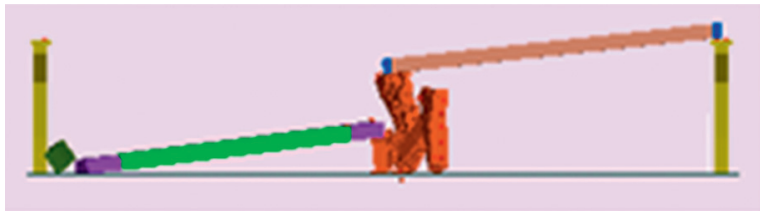

(g)

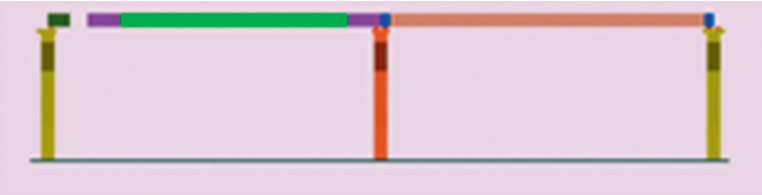

(b)

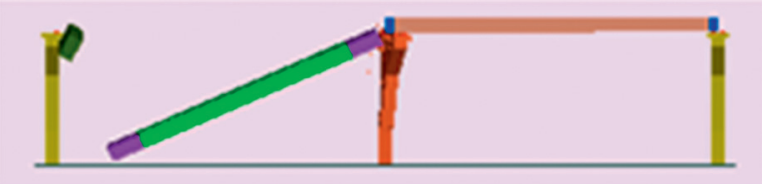

(d)

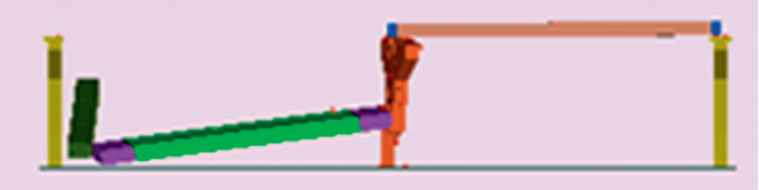

(f)

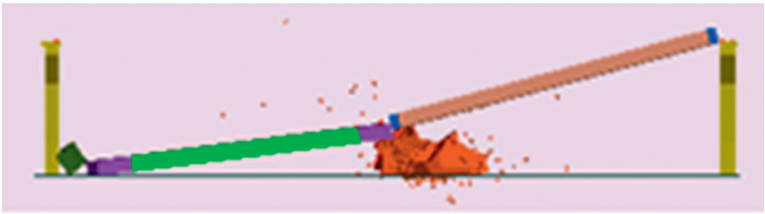

(h)

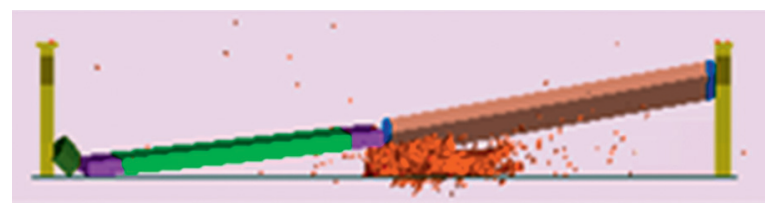

(i)

FIGURE 5: Graphical representation of the collapse procedure at (a) $t=0.00 \mathrm{~s}$, (b) $t=0.10 \mathrm{~s}$, (c) $t=1.24 \mathrm{~s}$, (d) $t=1.34 \mathrm{~s}$, (e) $t=2.10 \mathrm{~s}$, (f) $t=3.03 \mathrm{~s},(\mathrm{~g}) t=5.18 \mathrm{~s}$, (h) $t=5.82 \mathrm{~s}$, and (i) $t=6.22 \mathrm{~s}$. 

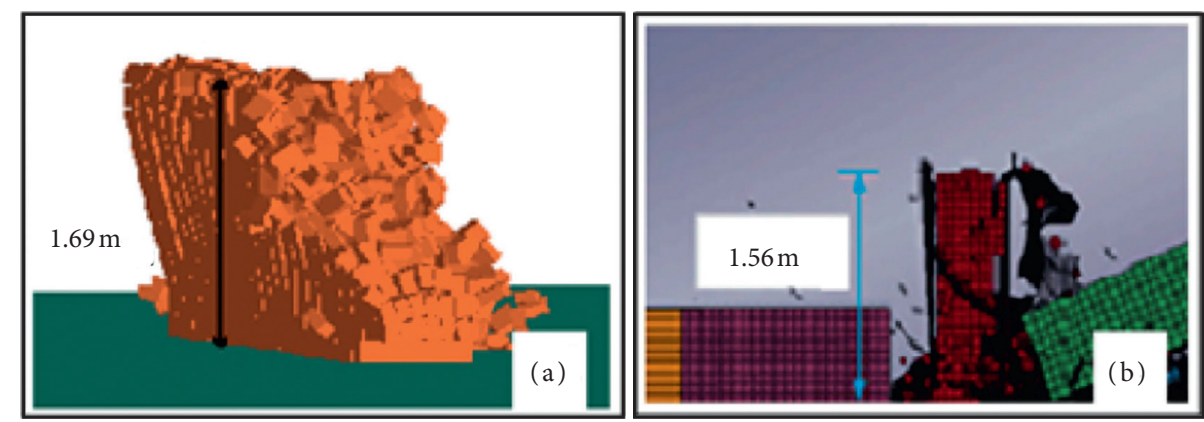

Figure 6: Comparison of the height of the remained part of pier \#109 obtained from (a) this study and (b) FEM analysis.

of piers as two commonly used alternatives for the bridge deck.

The deck in the first alternative (i.e., concrete girder-slab) was modeled using AASHTO type IV typical precast prestressed I-shaped concrete girders [22] in accordance with the studies reported by Darmawan and Stewart [23] for such simply supported spans of the same span length. As shown in Figure 8, seven prestressed concrete girders were used located $2 \mathrm{~m}$ away from each other together with a concrete slab of $20 \mathrm{~cm}$ in thickness. Middle and end diaphragms included all the spans located at $5 \mathrm{~m}$ away from each other in the span length.

The superstructure in the second alternative was modeled as concrete slab on steel girder, according to typical deck sections used by Maleki [21] for such simply supported spans of the same span length. Figure 9 shows a cross section of the deck, in which 9 steel girders of the W12 $\times 40$ (US Std.) profile were used located at $2 \mathrm{~m}$ away from each other together with a concrete slab of $19 \mathrm{~cm}$ in thickness. Also, there were middle and side diaphragms located at $5 \mathrm{~m}$ from each other in the span length.

When the deck with a distance of $1.4 \mathrm{~m}$ from the abutment was eliminated, it was observed that the left side of the deck fell down on the ground and the right side collided with the pier for all 3 models. As shown in Figure 10, all 4 spans of the voided slab bridge collapsed progressively whereas just 2 spans of girder-slabs collapsed. Collapse of 4span voided slab bridge was in good agreement with the results of field observation done after the incident.

As shown in Figure 11, due to the collision of the first deck with the piers, impacting forces of $23.5 \mathrm{MN}, 18.14 \mathrm{MN}$, and $10.30 \mathrm{MN}$ were applied to the first piers in concrete voided slab, concrete girder-slab, and steel girder-concrete slab bridges, respectively. Amount of impacting force in the voided slab bridge was more than that in the steel and concrete girder-slab bridges. However, it was much greater than the shear capacity of the pier $(4.62 \mathrm{MN})$ for all 3 alternatives. The differences in impacting force of the concrete voided slab bridge with the bridges designed in the validation test are attributed to the number of fallen hollow slabs (12 concrete hollow slabs in the validation model of Hongqi Bridge based on demolition plan and 16 concrete hollow slabs based on this section). The difference in impacting force on the pier of girder-slab bridges in comparison with the voided slab bridge is due to the smaller weight of girderslabs, so that the superstructure weight was equal to 620,480 ,

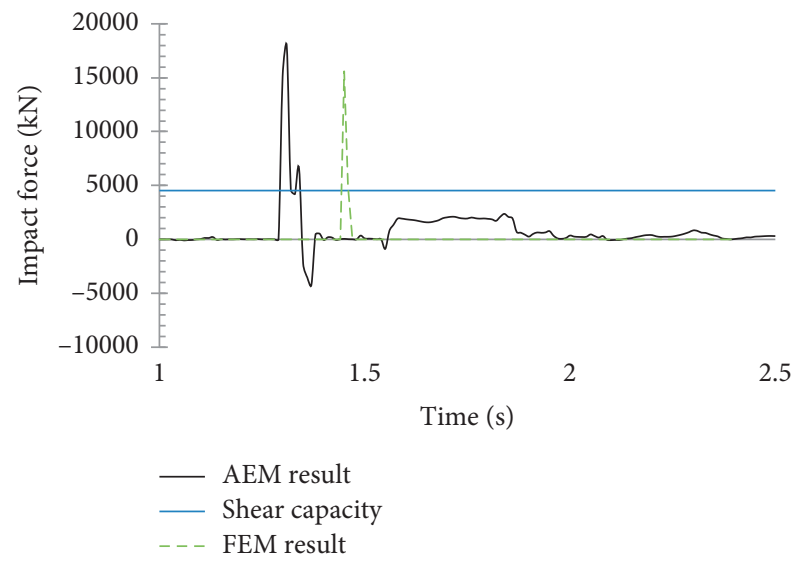

FIGURE 7: Comparison of the imposed impacting force on pier \#109 of Hongqi Bridge [15].

and 350 tons for voided slab, concrete, and steel girder-slab bridges, respectively.

Impacting force on the second and third piers of the voided slab bridge was in the range of $10 \mathrm{MN}$ for each pier that is also larger than shear capacity; therefore, the second and third piers collapsed owing to insufficient shear strength. It is notable that, contrary to the impact, the impacting force on the second and third piers was smaller than that on the first pier, although the weight of the superstructure of the second and third spans was larger than that of the first span (falling length of the first slab was $2.4 \mathrm{~m}$ smaller than the other slabs, because of the demolition plan), attributing to partial support provided by the debris of the first pier as well as relatively longer span length that led to a slightly smaller impact angle. In the case of the second pier, the value of impacting force dramatically decreased for both the girder deck types. The decrease in the impacting force for the second span can be due to the changes in the induced angle between the deck and the pier.

This shows that the probability of domino-type progressive collapse in the voided slab deck is far more than both the concrete and steel girder-slabs.

4.2. Effect of Type of Substructure. To investigate the effect of using different pier systems on PC of Hongqi Bridge, multicolumn bent piers with different numbers of the column were used. 4 multicolumn pier systems including 2- 


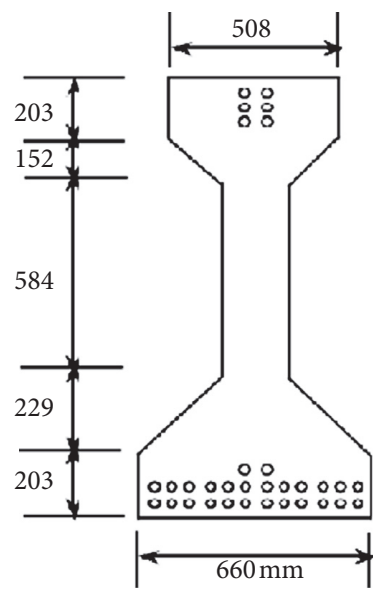

(a)

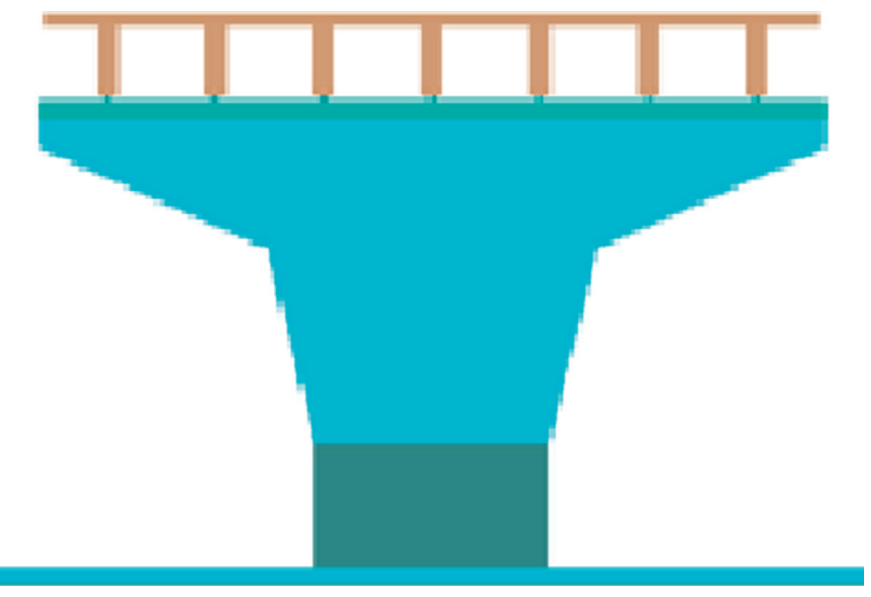

(b)

FIgure 8: Hongqi Bridge with concrete girder-slab: (a) girders' properties according to AASHTO and (b) modeling in AEM.

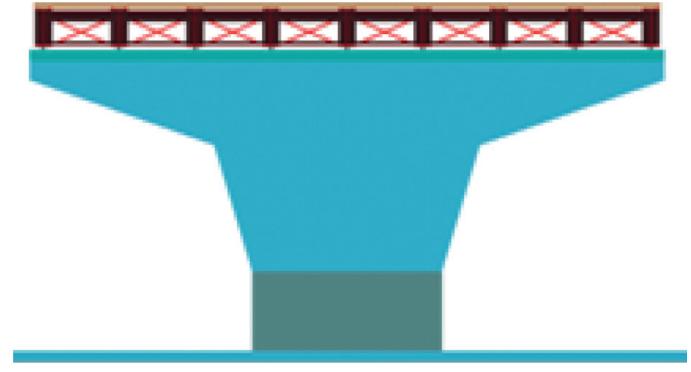

(a)

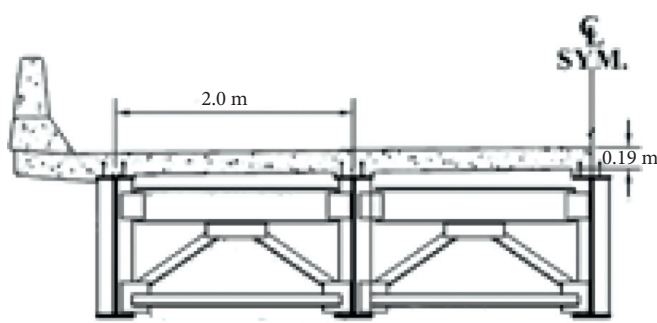

(b)

Figure 9: Hongqi Bridge with steel girder-slab: (a) girders' properties according to Maleki's research [21] and (b) modeling in AEM.
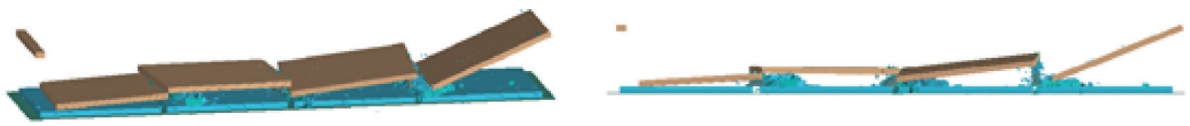

(a)
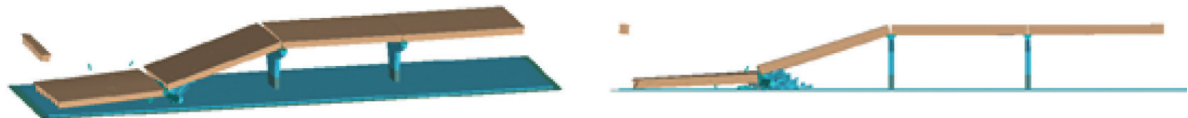

(b)
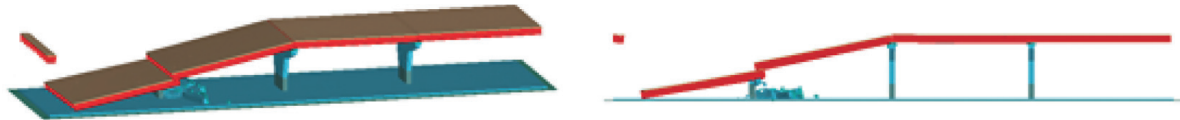

(c)

FiguRE 10: State of the models at the time of $12 \mathrm{sec}$ (a) hollow slab deck, (b) concrete slab on concrete girder, and (c) concrete slab on steel girder.

column, 3-column, 4-column, and 5-column piers were considered as shown in Figure 12. The columns were designed such that overall pier flexural capacity was the same as the rectangular pier of Hongqi Bridge, as shown in Figure 13. Table 1 presents some important dimensional and reinforcement details of the piers.

Similar to the previously explained procedure, $1 \mathrm{~m}$ of the first span was eliminated to investigate the collapse behavior of the bridges with different pier systems. Figure 14 shows the final configuration of the collapse procedure for different pier systems. According to this figure, in 2-, 3-, and 4column piers, collapse propagation was stopped in the second span, but in 5-column pier, it was stopped in the first span. Comparison of collapse procedure of Hongqi 4-span Bridge with rectangular pier illustrated in Figure 10(a), in which collapse propagated to all 4 spans, it seems that 


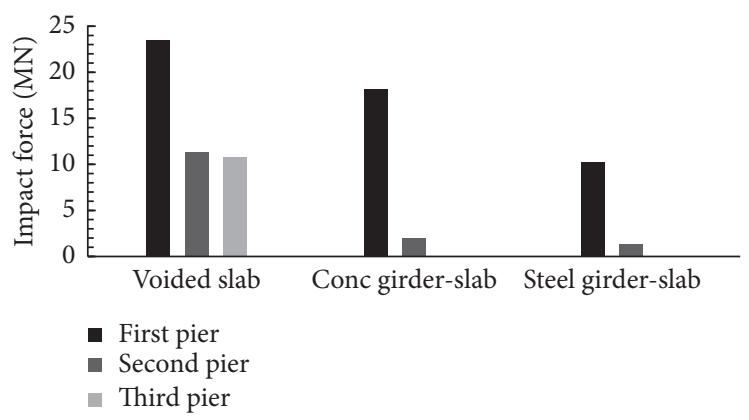

FIGURE 11: Impacting force on pier of the bridge with different superstructure systems.

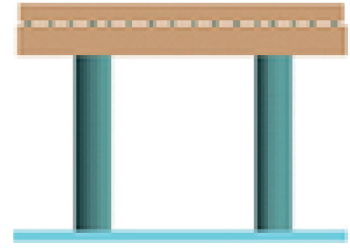

(a)

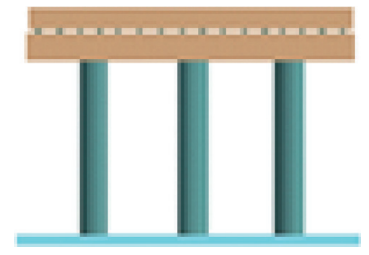

(b)

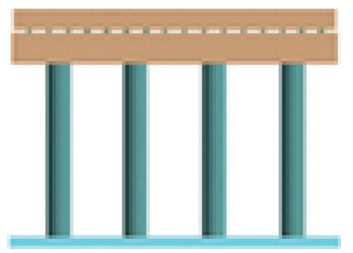

(c)

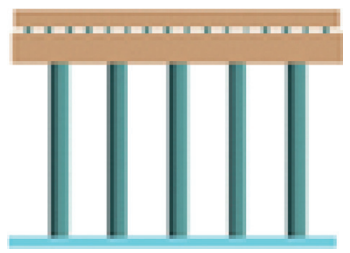

(d)

Figure 12: Different multicolumn pier systems: (a) two-column, (b) three-column, (c) four-column, and (d) five-column.

utilizing multicolumn pier instead of single pier increases indeterminacy of piers leading to a decrease in the probability of collapse propagation. In single-column pier, the occurrence of crack in a part of the pier propagates in the other areas, whereas in multicolumn piers, it propagates just in the same column. Figure 15 shows the values of impacting force on the piers. As depicted in Figure 15, with an increase in the number of columns in each pier, the value of impacting force decreases.

4.3. Effect of In-Span Hinges. In-span hinges are usually used for continuous-span bridges as shown in Figure 16 [24]. Although there are some weaknesses in the seismic response of in-span hinges, they can be considered as a good alternative to prevent PC of continuous-span bridges. It is noteworthy that, if this kind of deck system is designed incorrectly, it can be vulnerable to collapse, especially in strong grand motions or heavy accidents, but it also can effectively prevent collapse propagation and acts as a fuse in bridge deck. In this section, the effect of in-span hinges on PC of the bridge was investigated. To do this, 2 alternatives were used. In the first alternative, one hinge was placed in the middle of the first span, and in the second alternative, two hinges were placed in one-third of the length of the second span (it should be noted that the use of 2 in-span hinges in the first span leads to instability). Original deck of Hongqi Bridge was a simply supported deck which in this case, the deck was firstly modeled as a continuous-span with hingein-span and was redesigned to increase its bending resistance for the new system. Figure 17 shows bending moments in the length of the continuous deck due to dead and live loads. As shown in Figures 18 and 19, in both alternatives, the deck collapsed longitudinally up to the hinge location, and then the collapse process was stopped.

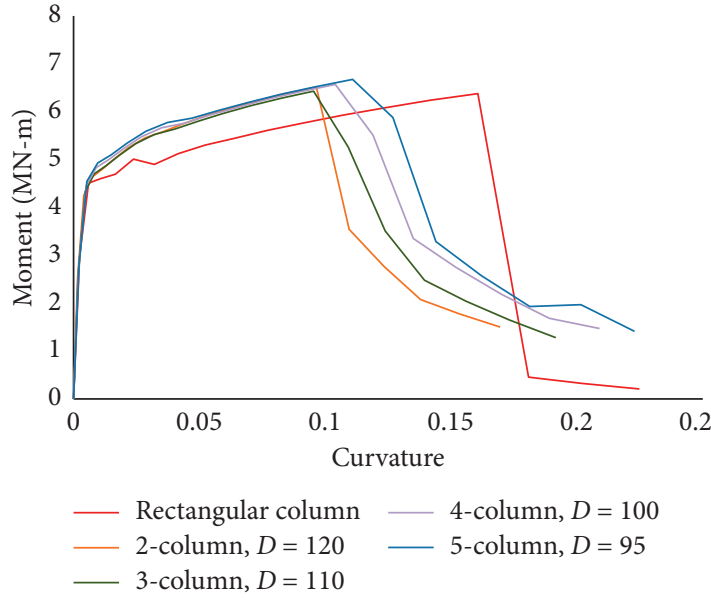

FIgURE 13: Moment-curvature diagrams of the different pier systems.

4.4. Effect of Restrainers. Since San Francisco earthquake in 1971, restrainers have been used and good performance of these cables has been reported in Loma Prieta (1989) and Northridge (1994) Earthquakes [25]. In practice, these cables limit displacements and act as an unseating prevention device for bridges. Figure 20(a) shows the location of the installation of the restrainers for retrofitting bridges in practice. In the AEM model, restrainers were added to the 4span bridge at connection of the deck and the abutment, as shown in Figure 20(b). Efficacy of the restrainers in deceleration of deck falling and reduction of impacting force was investigated by eliminating a seating part of the deck, as mentioned in the demolition plan of Hongqi Bridge.

The restrainers with yield strength of $1500 \mathrm{MPa}$ were used in the analysis with different cross-sectional areas. To find an appropriate dimension of restrainers, cross-sectional 
TABLE 1: Dimensional and reinforcement details of the pier systems.

\begin{tabular}{|c|c|c|c|c|}
\hline Type of pier & $\begin{array}{l}\text { Diameter of columns } \\
\qquad(\mathrm{m})\end{array}$ & $\begin{array}{l}\text { Reinforcement of columns } \\
\text { (m) }\end{array}$ & $\begin{array}{l}\text { Width of cap beam } \\
(\mathrm{m})\end{array}$ & $\begin{array}{l}\text { Longitudinal stiffness of column } \\
\qquad(\mathrm{MN} / \mathrm{m})\end{array}$ \\
\hline $\begin{array}{l}\text { Rectangular pier (original } \\
\text { bridge) }\end{array}$ & Variable in height & Variable in height & 1.20 & 45.07 \\
\hline Two-column & $D=1.20$ & $70 \Phi 18$ (spiral: $Ф 16 @ 7.5)$ & 1.30 & 47.35 \\
\hline Three-column & $D=1.10$ & 55Ф18 (spiral: Ф16@7.5) & 1.20 & 46.23 \\
\hline Four-column & $D=1.00$ & $48 \Phi 18$ (spiral: $Ф 12 @ 7.5)$ & 1.10 & 45.44 \\
\hline Five-column & $D=0.95$ & $38 \Phi 18$ (spiral: Ф12@7.5) & 1.05 & 46.24 \\
\hline
\end{tabular}

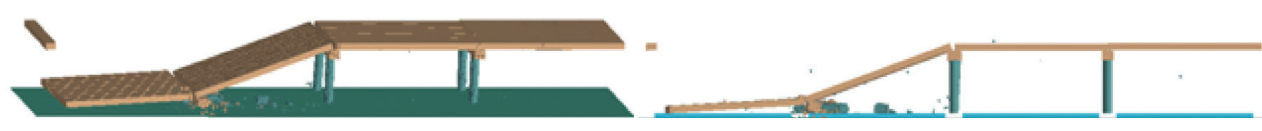

(a)

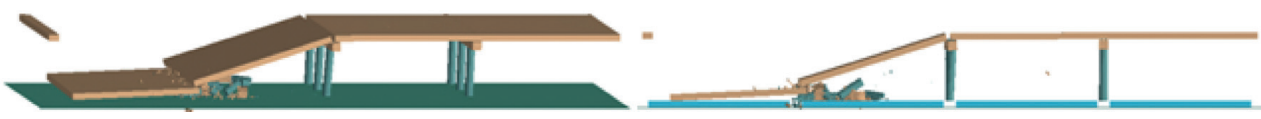

(b)
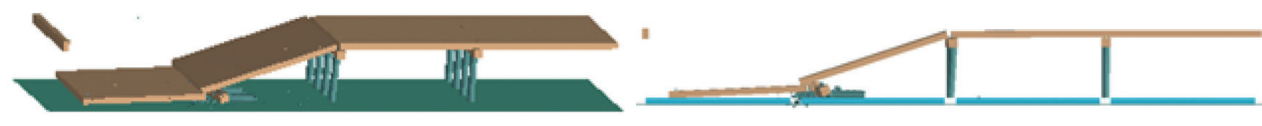

(c)
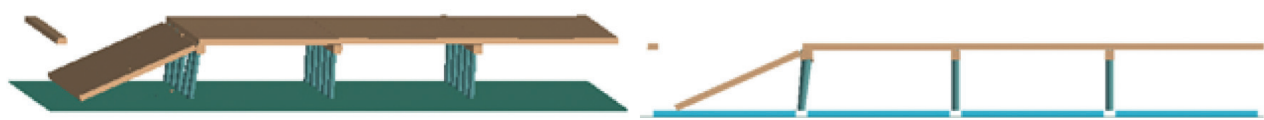

(d)

Figure 14: The collapsed position of the bridges with different pier systems. (a) 2-column pier $(D=1.2 \mathrm{~m})$. (b) 3-column pier $(D=1.1 \mathrm{~m})$. (c) 4-column pier $(D=1.0 \mathrm{~m})$. (d) 5-column pier $(D=0.95 \mathrm{~m})$.

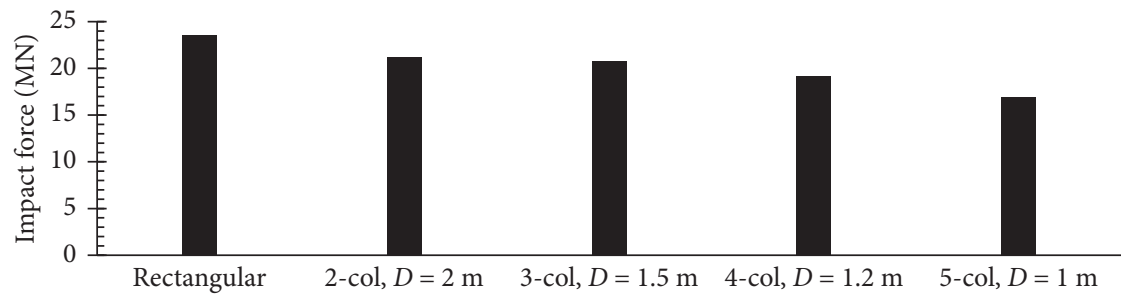

FIGURE 15: Impacting forces on the first pier of the bridges with different pier systems.

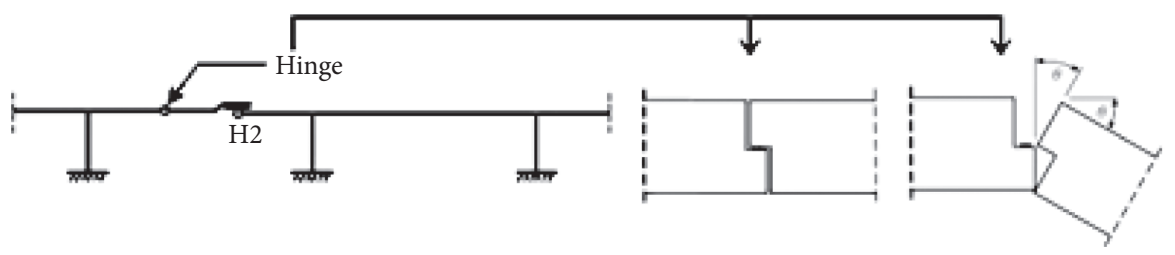

FIgURE 16: View of in-span hinges in bridge decks. 


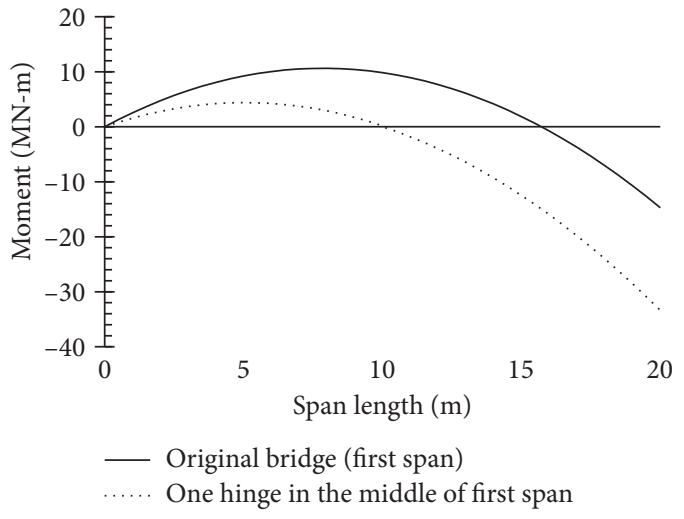

(a)

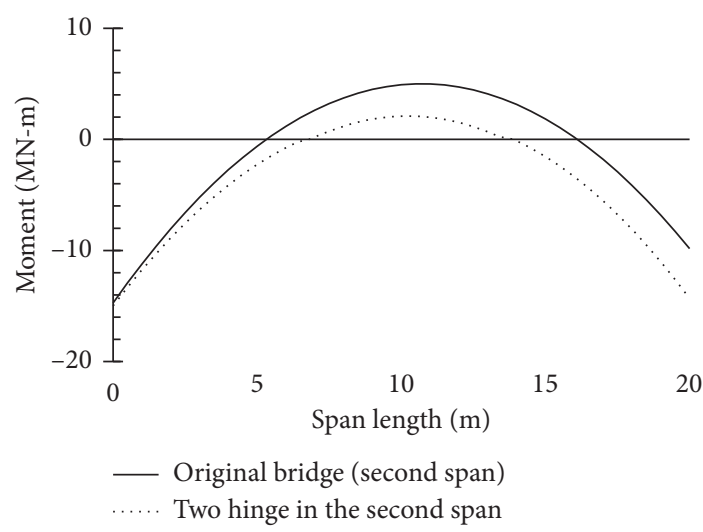

(b)

FIGURE 17: Diagram of the moment for (a) one hinge in the first span length and (b) two hinges in the second span length.
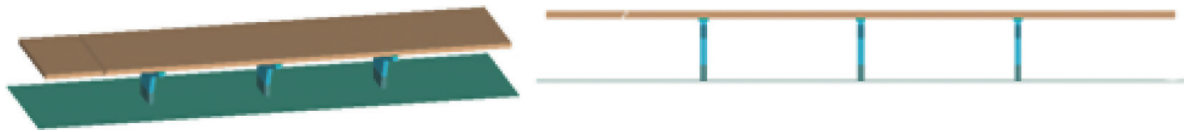

(a)
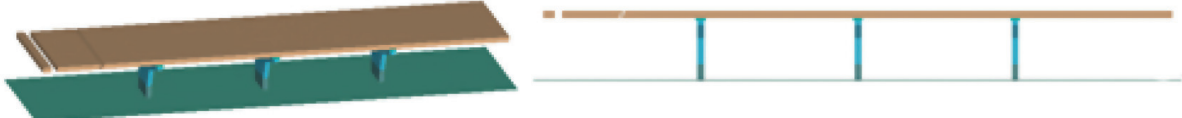

(b)
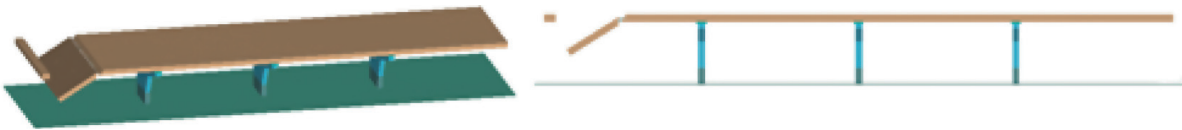

(c)
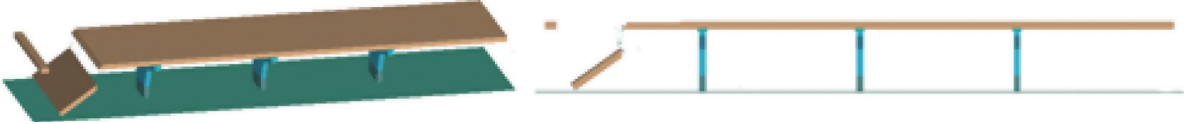

(d)
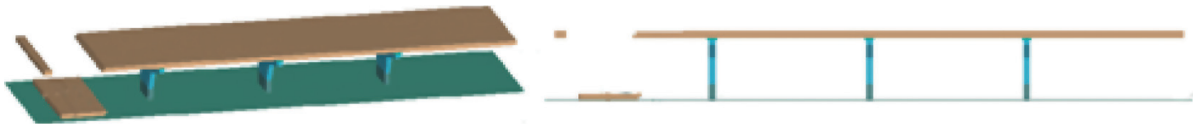

(e)

Figure 18: Collapse response of Hongqi Bridge in the case of one hinge in the first span: (a) $t=0.00 \mathrm{~s}$, (b) $t=0.10 \mathrm{~s}$, (c) $t=0.90 \mathrm{~s}$, (d) $t=1.46 \mathrm{~s}$, and (e) $t=8.00 \mathrm{~s}$.
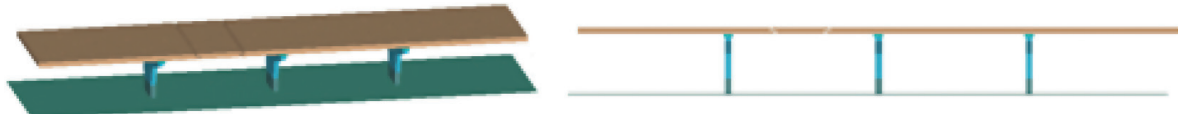

(a)
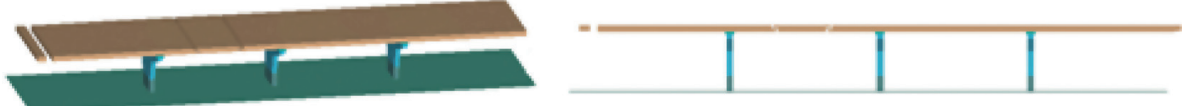

(b)

Figure 19: Continued. 


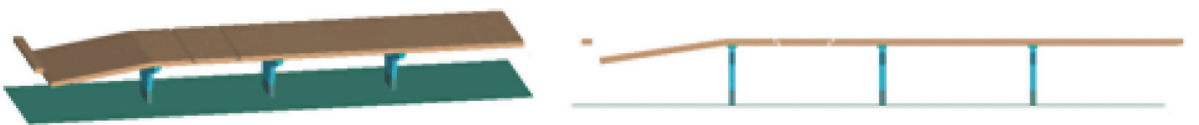

(c)
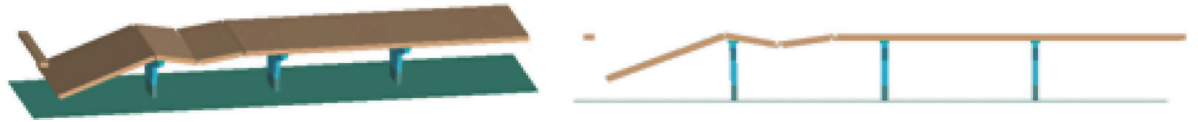

(d)
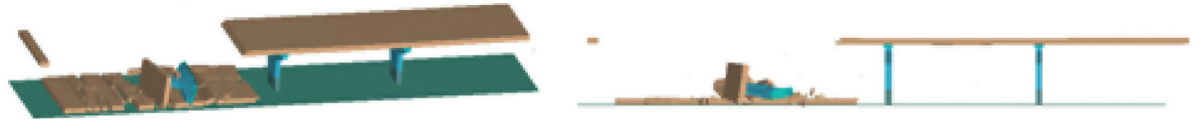

(e)

Figure 19: Collapse response of Hongqi Bridge in the case of two hinge in the second span: (a) $t=0.00 \mathrm{~s}$, (b) $t=0.10 \mathrm{~s}$, (c) $t=0.68 \mathrm{~s}$, (d) $t=1.40 \mathrm{~s}$, (e) $t=1.56 \mathrm{~s}$.

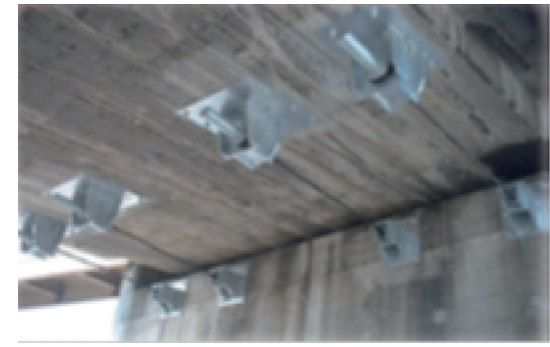

(a)

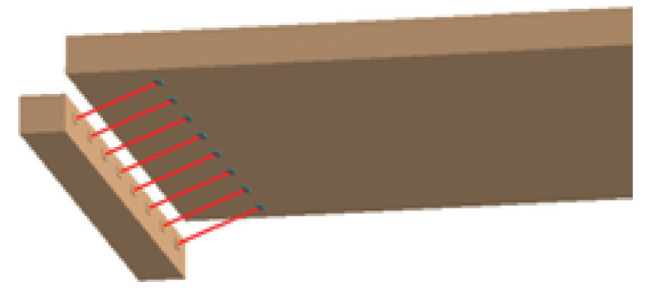

(b)

FIGURE 20: Using restrainer cables: (a) in practice and (b) in numerical modeling.

TABLE 2: Impacting force on the first pier of the bridge in the case of using restrain cables in the connection of deck to abutment.

\begin{tabular}{lcc}
\hline Cable area $\left(\mathrm{cm}^{2}\right)$ & First span collapse & First pier impacting force $(\mathrm{MN})$ \\
\hline 0 & Yes & 23.50 \\
4.16 & Yes & 22.18 \\
10.4 & Yes & 21.04 \\
19.20 & Yes & 17.05 \\
25.99 & No & 0 \\
\hline
\end{tabular}

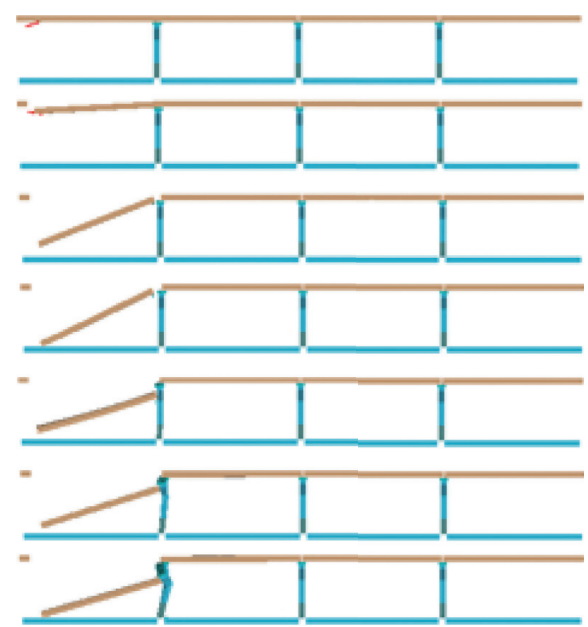

(a)

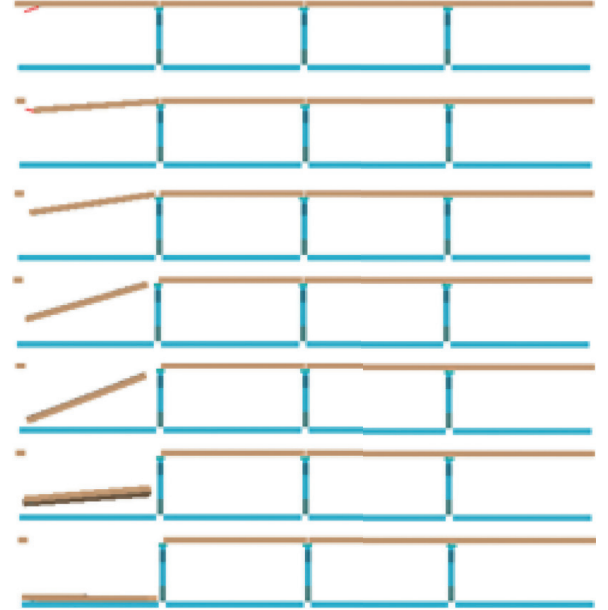

(b)

Figure 21: Collapse procedure of Hongqi 4-span bridge equipped with restrainers: (a) with inadequate cross-sectional area and (b) with adequate cross-sectional area. 
area and number of restrainers increased gradually. The procedure of the mechanical method of demolition was simulated in AEM, and nonlinear dynamic analysis was done for each incremental step. Table 2 presents the results of impacting force caused by deck-to-pier collision. According to results, as the number of cables increases, resulting impacting force decreases. This process can be continued until no collision occurs between the deck and the pier. Based on this table, installing the restrainers with a total cross-sectional area of more than $26 \mathrm{~cm}^{2}$ leads to the prevention of collision between deck and pier and as a result can stop collapse propagation. Figure 21 shows two models of the bridge with adequate and inadequate crosssectional area of restrainers for preventing the impact between the deck and the pier. Thus, this strategy can be regarded as a proper retrofitting solution for bridges against PC.

\section{Conclusion}

Hongqi Bridge collapsed progressively in May 2009 during the mechanical demolition process. In this incident, 9 spans with a total length of $180 \mathrm{~m}$ were destroyed and 9 people died unfortunately. In this study, the progressive collapse of Hongqi Bridge was simulated numerically, using the Applied Element Method. The model was firstly verified using field observations, and different effective factors were investigated after verification. Results of the present study are presented as follows:

AEM is a powerful method with high accuracy in simulation and prediction of structural collapse procedure.

Comparison of the results of impacting force and shear capacity of the piers showed that impacting force caused by deck-to-pier collision is several times more than shear capacity; hence, it is not reasonable to design the pier for this amount of force. It is better to prevent collapse propagation or deck-to-pier collision using other alternatives.

Based on a comprehensive study on different superstructure systems, it can be concluded that the amount of impacting force caused by deck-to-pier collision is more for the concrete voided slab deck compared to the girder-slab decks, attributing to its higher weight. It is also higher in the concrete girder-slab than in the steel girder-slab. Hence, the probability of extreme impacting force and collapse propagation increases in the decks with higher weight, after any initial failure.

Results of comprehensive study on different substructure systems showed that the probability of collapse propagation could be decreased using multicolumn piers in comparison with a single rectangular pier, which can be due to higher redundancy of the substructure.

In-span hinges can be considered as one of the practical design methods to prevent collapse propagation in continuous spans.
Since insufficient seating length in abutment is considered as one of the important effective factors in collapse initiation, the use of restrainers as a connector of the deck to abutment could decrease the probability of progressive collapse.

\section{Data Availability}

All of the internal information of this research has been extracted from "Domino-type progressive collapse analysis of a multi-span simply-supported bridge: A case study" which has been published in Engineering Structure Journal and it is attached to this paper.

\section{Conflicts of Interest}

The authors declare that they have no conflicts of interest.

\section{References}

[1] ASCE7-10, Minimum Design Loads for Buildings and Other Structures, American Society of Civil Engineering, Reston, VA, USA, 2010.

[2] U. Starossek, "Typology of progressive collapse," Engineering Structures, vol. 29, no. 9, pp. 2302-2307, 2007.

[3] H. Hao, C. Wu, Z. X. Li, and A. K. Abdullah, "Numerical analysis of structural progressive collapse to blast loads," Transactions of Tianjin University, vol. 12, pp. 31-34, 2006.

[4] J. Li and H. Hao, "Numerical study of structural progressive collapse using substructure technique," Engineering Structures, vol. 52, pp. 101-113, 2013.

[5] O. A. Mohamed, "Progressive collapse of structures: annotated bibliography and comparison of codes and standards," Journal of Performance of Constructed Facilities, vol. 20, no. 4, pp. 418-425, 2006.

[6] H. M. Salem, A. K. EL-Fouly, and H. S. Tagel-Din, "Toward an economic design of reinforced concrete structures against progressive collapse," Engineering Structures, vol. 33, no. 12, pp. 3341-3350, 2011.

[7] A. G. Lichtenstein, "The silver bridge collapse recounted," Journal of Performance of Constructed Facilities, vol. 7, no. 4, pp. 249-261, 1993.

[8] U. Starossek, "Progressive collapse of structures," vol. 153, Tomas Telford Ltd., London, UK, 2009.

[9] A. Astaneh-Asla, "Progressive collapse of steel truss bridges, the case of I-35W collapse," in Proceedings of the 7th International Conference on Steel Bridges, Guimarăes, Portugal, June 2008.

[10] Q. Han, X. Du, J. Liu, Z. Li, L. Li, and J. Zhao, "Seismic damage of highway bridges during the 2008 Wenchuan earthquake," Earthquake Engineering and Engineering Vibration, vol. 8, no. 2, pp. 263-273, 2009.

[11] A. Ibarhim, S. Hani, and N. Rahman, "Progressive collapse of post-tensioned box girder bridges under blast loads using applied element method," in Proceedings of the Structures Congress, pp. 2291-2300, Chicago, IL, USA, March 2012.

[12] Y. E. Lu and L. M. Zhang, "Progressive collapse of a drilledshaft bridge foundation under vessel impact," Ocean Engineering, vol. 66, pp. 101-112, 2013.

[13] Z. Xu, X. Lu, H. Guan, X. Lu, and A. Ren, "Progressivecollapse simulation and critical region identification of a stone 
arch bridge," Journal of Performance of Constructed Facilities, vol. 27, no. 1, pp. 43-52, 2012.

[14] H. Salem and H. Helmy, "Numerical investigation of collapse of the Minnesota I-35W bridge," Engineering Structures, vol. 59, pp. 635-645, 2015.

[15] B. Kaiming, W. Ren, P. Cheng, and H. Hao, "Domino-type progressive collapse analysis of a multi-span simply-supported bridge: a case study," Engineering Structures, vol. 90, pp. 172-182, 2015.

[16] A. Seyed khoei, R. Akbari, and S. Maalek, "Earthquake-induced domino-type progressive collapse in regular, semiregular, and irregular bridges," Journal Shock and Vibration, vol. 2019, Article ID 8348596, 18 pages, 2019.

[17] H. Tagel-Din and K. Meguro, "Applied element simulation for collapse analysis of structures," Bulletin of Earthquake Resistant Structure Research Center, vol. 32, pp. 113-123, 1999.

[18] H. Tagel-Din and K. Meguro, "Applied element method for dynamic large deformation analysis of structures," Doboku Gakkai Ronbunshu, vol. 2000, no. 661, pp. 1-10, 2000.

[19] H. Okamura and K. Maekawa, Nonlinear Analysis and Constitutive Models of Reinforced Concrete, Gihodo-Shuppan, Tokyo, Japan, 1991.

[20] D. Ristic, Y. Yoshikazu, and I. Hirokazu, "Stress-strain based modeling of hysteretic structures under earthquake induced bedning and varying axial loads," Research Report No. 86-ST01, School of Civil Engineering, Kyoto University, Kyoto, Japan, 1986.

[21] S. Maleki, "Deck modeling for seismic analysis of skewed slabgirder bridges," Engineering Structures, vol. 24, no. 10, pp. 1315-1326, 2002.

[22] AASHTO, LRFD Bridge Design Specification, American Association of State Highway and Transportation Officials, Washington, DC, USA, 2010.

[23] M. S. Darmawan and M. G. Stewart, "Spatial time-dependent reliability analysis of corroding pretensioned prestressed concrete bridge girders," Structural Safety, vol. 29, no. 1, pp. 16-31, 2007.

[24] A. Ghali and G. Tadros, "Bridge progressive collapse vulnerability," Journal of Structural Engineering, vol. 123, no. 2, pp. 227-231, 1997.

[25] D. Cardone, G. Perrone, and S. Sofia, "Seismic response of simply supported deck bridges with auxiliary superelastic devices," Procedia Engineering, vol. 14, no. 14, pp. 2315-2322, 2011. 